
Resistance to nuclear power continues. We report on concern over nuclear waste in the
United States and Holland and a row over the supplv of enriched uranium to Brazil

\author{
Sorry, for copyright \\ reasons some images \\ on this page may not \\ be available online
}

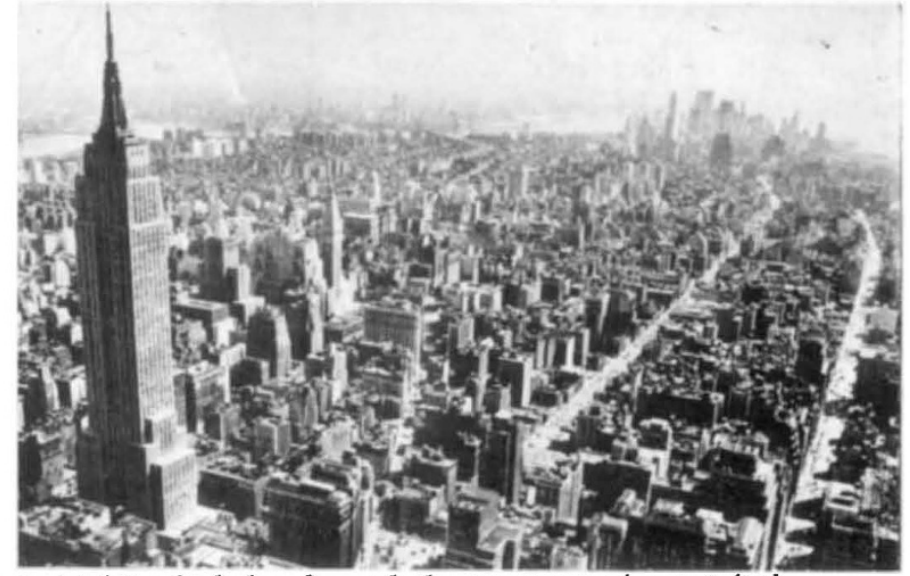

Building Brazil's first nuclear power station (left) and New York (right) which has banned the transport of spent fuel

\title{
Nuclear waste ban threatens research at Brookhaven laboratory
}

\section{David Dickson discusses how a dispute on the transportation of nuclear wastes reflects scientific and political uncertainties about waste management policy}

THE Brookhaven National Laboratory at Upton, Long Island, last week asked New York City's health department for special permission to transport a limited number of spent fuel elements from its High Flux Beam Reactor through the streets of the city.

The request is the latest move in a dispute between the laboratory and the city which has been simmering since 1976, when the city placed a ban on the transport of waste material which could, if unresolved, eventually impinge directly on research activities at the laboratory.

Since 1976, spent fuel from the reactor, which had previously been shipped for storage and processing at the Savannah River Plant in South Carolina, has been stored on site. Plans to ferry the fuel across to the Connecticut shore were frustrated when New London imposed an ordinance similar to the New York ban, and as the storage facilities at Brookhaven begin to fill up, plans to double the size of these facilities are now having to be drawn up.

In the short-term, scientists at the laboratory, which is run by a consortium of nine universities under contract to the Department of Energy, are concerned that the extra money for building new - and, some claim, unnecessary - storage facilities will have to be taken directly out of the laboratory's research budget.

In the longer-term, some are even claiming that if the New York ban remains in force and problems are experienced in getting agreement on further on-site storage, closing down the reactor, which is a major research facility for fields ranging from materials science to molecule biology, cannot be ruled out. "It seems rather a wild fear, but given the general irrationality with which many of these matters now seem to be dealt, it perhaps becomes more and more real," Dr Martin Blume, associate head of the physics department, said last week.

Brookhaven's problems reflect the extent to which the whole issue of nuclear waste management has become the Achilles heel of nuclear power. The problem is not just the technical one of providing a means of disposing waste fuel, but also involves public acceptability of the means proposed.

Earlier this year, for example, the California state legislature vetoed plans for the $\$ 3$ billion Sundesert nuclear power plant after the San Diego Gas and Electric Co had failed to convince a state legislative committee that adequate waste disposal facilities were available. Several other states have since followed California's lead.

In the past, the tendency has been to blame the indecision of policymakers; one is often told that the problem is " $10 \%$ science and $90 \%$ politics". Responding to such criticism, the Carter administration has recently made a concerted effort to confront the issue, including setting up an Interagency Task Force earlier this year to draw up proposals for an inte- grated waste management policy.

As the issues have been studied increasingly closely, however, doubts have begun to arise about the priority that has been given to two most conventionally accepted methods of waste disposal - containing the waste in glass and depositing it in salt formations.

Earlier in the summer, for example, the US Geological Survey issued a report by a team of scientists which, although repeating assurances that acceptable underground repositories for radioactive wastes can be constructed, pointed out that there were a number of geologic stumbling blocks which had to be dealt with first.

In the case of buried beds of rock salt, for example, the report says that many questions concerning the behaviour of rock salt and its high solubility must be resolved, such as the fact that relatively small amounts of brine appear to cause a substantial decrease in mechanical strength that would permit movement of waste during a relatively short time.

As far as the primary containment of waste is concerned, a report recently issued by a panel of the National Academy of Science's Committee on Radioactive Waste Management comes to the conclusion that, although glass may be adequate for the implementation of large-scale solidification programmes, "it cannot be recommended as the best choice, especially for older Department of Energy wastes."

The panel, which was chaired by Professor Rustum Roy of Penn State University, says that the preference for glass as a waste form has been mistakenly based on the assumption that low leachability is the major criterion 
for solid waste management, and "on a misreading of the 'stability' of glass under repository conditions."

It recommends that, as an alternative to glass, cement-based composites and low-temperature ceramics should be researched vigorously as the prime candidates for solidification of DoE wastes, an approach given wide publicity by Professor A. E. Ringwood of the Australian National University last month, and which has been closely studied in the US for a number of years.

Such challenges to the conventional scientific wisdom on nuclear waste disposal, many of which have resulted from the growing involvement of geochemists into a field previously dominated by physicists and engineers, has led the Department of Energy to broaden considerably the scope of its research options. In addition to salt formations, for example, there are now active programmes investigating the suitability of other geological media such as basalt, granite and shale.

At the same time, the department is adopting a more holistic approach to the waste management problem. Dr John Deutch, head of the Department's Office of Energy Research, told a Senate committee two weeks ago that the selection of a particular site for its environmental qualities could be more important than the choice of a particular medium.

"It is very important that the entire environment of a site is evaluated, in particular its chemical, geological and hydrographical characteristics", Dr Deutch told the committee, adding that "the problems of finding a site, even for just assessing, are formidable."

Such problems are illustrated by the Department's current plans to construct a Waste Isolation Pilot Plant (WIPP) in salt beds near Carlsbad in New Mexico. The nuclear industry is keen that the department should move ahead rapidly with its plans for WIPP, thus demonstrating that the safe disposal of radioactive waste is feasible.

However, local environmental groups in New Mexico, drawing attention to the USGS and other reports which point to current gaps in knowledge about the behaviour of salt - as well as the problems of later retrievability of the waste from salt deposits-are challenging the department's plans on the grounds that other geological media might be more appropriate for such a demonstration plant.

Both the frustration of the nuclear industry, and the concern of environmentalists, stems partly from the fact that the more research that is done into methods of waste disposal, the more scientists are realising that important gaps in knowledge still remain.

A recent report prepared by the

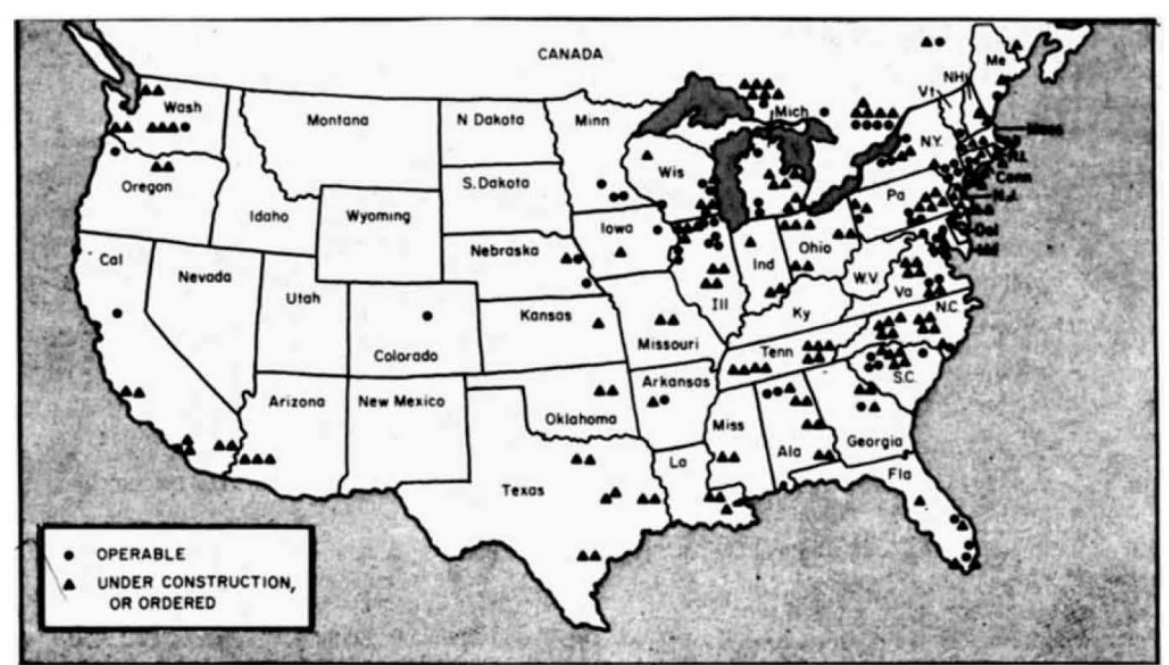

The size of the waste problem: America's nuclear reactors

Map taken from Oceanus, adapted from data supplied by Nuclear News, September 1976 and from US ERDA

Office of Science and Technology Policy for the President's Interagency Task Force, for example lists "numerous limitations of our knowledge" in hydrogeology, geochemistry and rock mechanics, "relatively young sciences with little experience in making or evaluating predictions that cover time frames even as short as a few decades".

The OSTP report adds that, despite such limitations, "we believe that such gaps in our knowledge need not rule out successful underground containment of radionuclides for periods of many thousands of years". Yet while such gaps exist, the question of the "adequacy" of proposed disposal-and even transportation-methods remains open to active debate.

It was the lack of federal regulation concerning the transportation of nuclear wastes, for example, that led the US Department of Transportation to issue a decision earlier this year supporting New York City's right to impose the ban that has prevented Brookhaven from shipping its spent fuel to South Carolina, and agreeing that, under the terms of the Hazardous Material Transportation Act, the ban could not be pre-empted by federal action.

The laboratory is at present contesting the constitutionality of the ban. "The laboratory does not acknowledge the validity of New York City's ban and New London's ordinance on the transportation of spent fuel elements through these cities", according to $\mathrm{Mr}$ Michael Goldman, an attorney for the universities which operate the laboratory. "But we would like to begin shipping spent fuel elements this fall to ensure that there is no interruption of research at the reactor."

Opponents of the ban point to a recent report from the Sandia Laboratories claiming that the transport of radioactive waste through urban areas poses a relatively low risk. Supporters, such as Friends of the Earth, claim that this study was coloured by the fact that it was commissioned by a government agency keen to validate its claims that federal legislation should pre-empt local regulations.

Some guidance will no doubt be provided by the Interagency Task Force when it presents the results of its deliberations to President Carter at the beginning of October; the Department of Transportation, for example, is preparing a study for the task force on the transportation of waste, and the Brookhaven case should figure prominently in its deliberations.

Ironically, current work at the reactor involves a variety of research projects in the health and environmental fields, including not only a study of trace elements and pollutants in the environment, but also an analysis of air samples for the New York State Department of Health.

\section{Nuclear moratorium}

Wisconsin has become the fourth US state to place a moratorium on the future construction of nuclear power plants in the light of current uncertainty over running costs, the availability of nuclear fuels, and safety aspects of waste disposal and decommissioning.

In announcing the moratorium last Friday, the state's Public Service Commission joined similar bodies in three other states-California, Iowa and Maine-which are pressing the Federal Government for firm guidance on such issues.

Conceding that nuclear power had an "impressive record" in Wisconsin, State Governor Martin Schreiber said its performance in other states "produces doubts that it is economically preferable to other forms of energy, energy conservation and alternative renewable energy sources. 